\title{
THE EFFECT OF NEW TECHNOLOGY APPLICATION ON THE COMMUNITY ENTHUSIASM
}

\author{
Religiana HENDARTI ${ }^{*}$, and Tota P. KASIH ${ }^{2}$ \\ ${ }^{1}$ Department of Architecture, Faculty of Engineering, Bina Nusantara University, Jakarta, Indonesia, \\ ${ }^{2}$ Professional Engineer Program Department, Faculty of Engineering, Bina Nusantara University, Jakarta, Indonesia \\ *rhendarti@binus.edu
}

\begin{abstract}
This paper presents a study on the influence of the introduction of an applied technology on the society enthusiasm. This paper focused on how technology impact on the society participation. The study observed how the society reacted and accept the introduced technology. The method of this study was observation and used descriptive analysis for the two cases. The cases are the application of pyrolysis converting plastic waste to liquid fuel and the solar panels for the alternative energy of aerator. This study refers to the terminology of Technopilia, and the indicators used to assess the enthusiasm are the enthusiastic and the participation The results showed that the reaction of the society was positive and openly accept the introduced technology. This can be seen from the enthusiasm of their participation in the application in the field.
\end{abstract}

Keywords: Effect, Enthusiasm, Participation, New Technology

\section{BACKGOUND}

It is well acknowledged that science and technology have had a major impact on society. By drastically changing our means of communication, the way we work, our housing, clothes, and food, our methods of transportation, and, indeed, even the length and quality of life itself, science has generated changes in the moral values and basic philosophies of mankind and to improve human conditions. In other words, science can be considered to be the foundation strength of society. However, this foundation strength is not something that can be acquired in a single day or night, but instead requires a steady, continuous build-up.

In the twentieth century, the exponential growth in various technical fields and the emergence of modern technologies (consecutive, especially to the progress of computer science) caused the appearance of the psychological ambivalence, because, modern technologies, generate, in the same measure, comfort and disasters

The person attracted to technology, the "technophile", takes the most or all technologies in a positive manner, enthusiastically adopting new forms of technology and view this as a way to improve his living conditions and combat social problems (Amichai-Hambrurger, 2009). The person attracted to technology, the "technophile", takes the most or all technologies in a positive manner, enthusiastically adopting new forms of technology and view this as a way to improve his living conditions and combat social problems (Amichai-Hambrurger, 2009).

The reason for which, in this article we intend to "linger" on psychological implications. Technophilia (from the Greek $\tau \dot{\varepsilon} \chi \nu \eta$ - technē, "art/ artifact, skill and understanding" and pí $\lambda$ o - philos, "love"), refers generally to the enthusiasm generated by the use of technology, particularly new technologies, such as: personal computers, Internet, mobile phones and even the technologies of "home cinema". The term emerged in the 1960s, is mainly used in sociology, when is examinated the interaction between individuals and society. Technophilia is a strong enthusiasm for new technologies such as Computers and the Internet. Technophiles can be described as geeks who are obsessed with technology. Unlike a technophobe, technophiles believe technology will make their lives more efficient. According to English meaning, enthusiasm means that interest big in something and the desire that makes a person par anticipate in it. Enthusiasm is a feeling of joy towards something will happen. As for indicators in student enthusiasm among students' other races; response, attention, concentration, awareness and will arise in students without coercion or order.

In relation to that, Bina Nusantara University has a vision to become a world-class university, fostering and empowering the society in building and serving the nation, whereas it become the basis for lecturer to be more active in empowering society activities. This study is essentially to seek the impact of the introduced technology on the society respond. This paper provides 2 (two) cases with the background of the local issues. The issues are plastic waste and the energy alternative for electricity for a fish culture. The selected community is namely "Komunitas Taman Sehat Alfadillah or Healthy Garden Community". This community is a community that has several activities that relate to green activities, such as doing a hydroponic garden, fish culture and collecting plastic waste. The issues that rise from this activity are: (1) how to recycle the plastic waste and (2) how to provide electricity for the aerotor. Aerator is a device to produce oxygen and to neutralize the water.

The study was conducted by observation and then the analysis is using descriptive method. The indicator of the anthusiasm is by how the community response the technology and how they parcipate in the application process. The participation can be determine by how the fullfill the schedule time in the site application

\section{THE COMMUNITY BACKGROUND}

The people who will be used as objects of community service are residents of RT 03 from RW 04, South Meruya Village, Kembangan District, West Jakarta. This community is incorporated in a community called 
the Al Fudhollah Healthy Garden Community. This community consists of not only retirees, but also local youths. They have an area planted with various plants and there is also a tilapia and catfish pond. Therefore, they call their community following their main activity.

This healthy park is not only for the activities of its members but also for their income. They sell their crops to the local community, as well as the results of their fish culture. In addition, one of the efforts being made is the selection of waste and hydroponic plants. The selection of this waste has compensation given to the youth here, as well as hydroponics .

This activity has been running quite well and the results can be enjoyed by people in need. Youth here also participate and there are training activities for this activity. The social conditions of the people are quite heterogeneous, there are upper middle class and lower middle class. The upper middle class is not quite as numerous as those from the lower middle class, but the social conditions are quite good. This is mutual respect and mutual help among its citizens.

Currently, there are efforts from the mosque management community in this area, namely the Al Fudholah Mosque, which is quite attentive to this issue. This mosque is located in RT 03, RW 04, Meruya Selatan sub-district, Kembangan district, West Jakarta. The administrators try to provide facilities for these young people who do not work to take care of the waste that is in the home environment in RT 03. One of the efforts is to sort the waste which is then taken to a storage area near this neighborhood. Currently, one of the efforts being pursued is the selection of waste and hydroponic plants. The selection of this waste has compensation given to the youth here, as well as hydroponics. This activity has been running quite well and the results can be enjoyed by people in need.

As for the fish farming, currently, fish farming in urban areas is starting to be widely carried out by the community, especially during the Covid pandemic. This is because not only do people have more time at home, but also to become an alternative source of family income. This is also because many companies are laying off their employees due to the Covid pandemic. However, the existing fish farming requires a tool to neutralize water conditions and as a provider of oxygen. This tool is called an aerator. However, because the location of the pool in some places cannot be reached with the convenience of electricity and must also be used for 24 hours, the electricity cost becomes quite expensive. One of the renewable energy providers is solar energy. Therefore, this activity is the application of solar energy technology for aerator equipment.

Floating PV systems for cultivation can become offgrid PV systems. The energy harvested is only for cultivation needs because the PV panel area is very minimal. The main use of the harvested energy is aerotor to maintain water conditions. Therefore, the diagram can be illustrated in Figure 2. As shown in the figure, it is recommended to use an aerotor type that uses direct current (DC), thereby reducing the space in the inverter.

\section{RESULTS AND DISCUSSION}

\section{Case one: Plastic waste}

As explained above, one of the efforts of the community or mosque management is to help young people who do not have jobs to earn income, one of which is waste sorting.

The problem faced by partners today is how to increase the value of this waste sorting activity. Currently, the activities are only in the form of sorting and the results of the sorting are given to the garbage collectors.

There are two main aspects of the problem at hand: (1) Waste problems, namely how to increase the value of waste, this waste sorting activity is not optimal, because it does not add value or value to waste, (2) The problem of unemployment, what is meant here is that many young people are reluctant to work with waste, so how to provide jobs that are still related to waste by using technology. So that other solutions are needed that in addition to increasing the value of waste, can also attract youth to work with waste and get better economic benefits.

The resulting output is a waste processing process with more effective technology. One of them with pyrolysis technology. This technology can be used as an example that may be developed and produced by yourself. So it is possible that the results of the oil will be sold or produce the pyrolysis process itself (Figure 1).

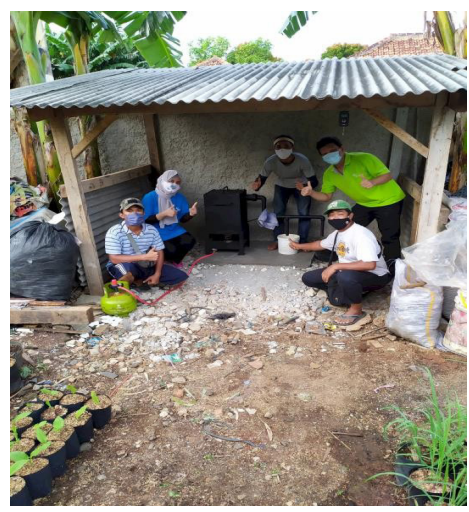

Figure 1. Pyrolisi that convert plastic waste to fuel energy

\section{Case 2: electricity source for aerator}

The need for an aerator to help provide oxygen in the tilapia pond. Currently used is to use a regular shower. Another problem is that there is no electrical connection close to the fish pond area, making it difficult to install an aerator. Therefore, the use of solar energy can help in providing electricity for the aerator. Then, how to make a tool that integrates solar panels and aerator for the aqua culture.

The solution offered by us was providing floating PV panels. The floating PV panels was constructed from bamboo material as the local material. The bamboo is quite many sale in this area (Figure 2). 


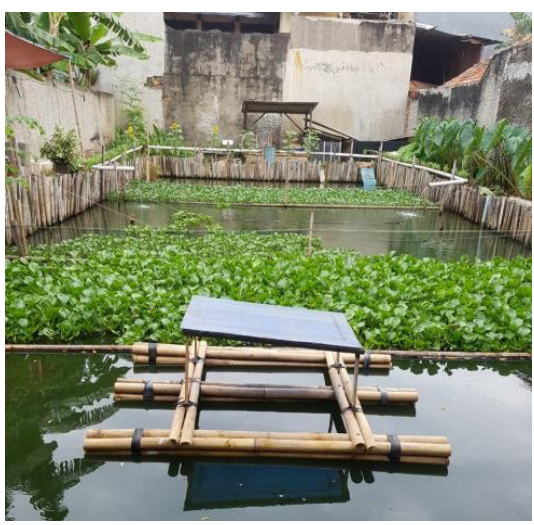

Figure 2. The aqua culture with the PV panels.

\section{THE COMMUNITY ENTHUSIASM}

As previously mentioned, that this paper presents the study of the people respond based on the "Technopilia". The indicators used here are how was the participation of the society and how they have responded to the new technology. Essentially, the technophile sees technology is something positive, therefore they not only accept but also use the technology. This type of society perceive new technology is a way to improve life and to address social problems. This view of acceptance in a society can be shown from their enthusiasm, since enthusiasm means of a big interest in something that makes a person par anticipate in it. As for the indicators, this study observed: (1) the response of the society with the introduced technology and (2) the participation in the process.

From the observations, it can be seen that the society response enthusiastically to the introduced technology. The leader of the community invited local government to see the activity of Pyrolysis experiment. The society also showed their interest in learning the chamber. As for the application of the solar panels for the aerator the enthusiasm was shown by their participation in constructing the floating construction (Figure 3).

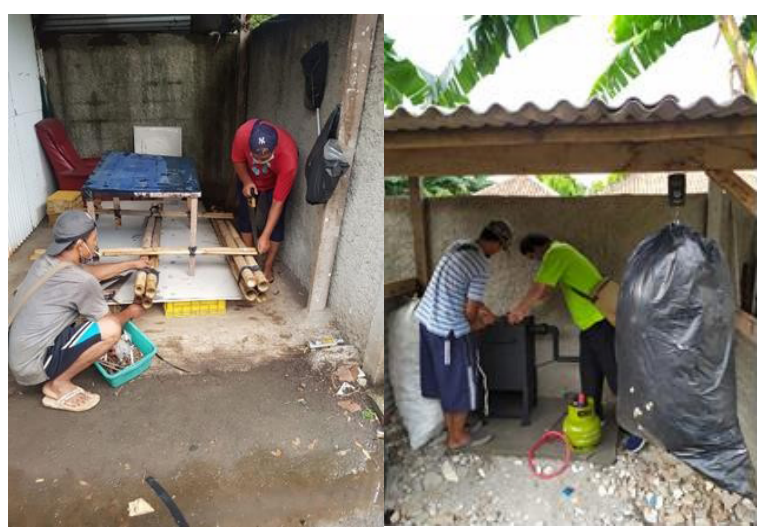

Figure 3. The enthusiasm of the society to the introduced technology

\section{CONCLUSION}

The study on how society respond to a new technologies has some remarks and they are as follows:

- The respond of the society is very welcome with the introduced technologies, it is shown from their participant in the applications.

- The communities has shown their enthusiasm by inviting local government to attend the activities .

This study also analyzed that the community is essentially already familiar with new technology and also has previous experience in implementing some new technology. Additionally, it is acknowledge that the response of the community is high since this technology support their needs for their aquaculture and their environment, which in consequence it impacts on their economic.

\section{REFERENCES}

Amichai, Yair-Hamburger. (Ed). (2009). Technology and Psychological Well Being, United States of America. Cambridge University Press.

Compton, C. William. (2005). An Introduction to Positive Psychology. United States of America, Thomson Learning Inc

James, B, et.al., 1985, The impact of science on society, Langley Research Center, Scientific and Technical Information Branch, National Aeronautics and Space Administration, Washington, DC

Luyao Liua, et.al., 2017, Power Generation Efficiency and Prospects of Floating Photovoltaic Systems, Energy Procedia 105 pg 1136 - 1142

Maria-Elena, O, (2015), Psychological Implications of Modern Technologies: "Technofobia" versus "Technophilia", Procedia - Social and Behavioral Sciences, Vol. 180, pages: 1137-1144. 